\title{
Proteasome inhibitor lactacystin enhances cisplatin cytotoxicity by increasing endoplasmic reticulum stress-associated apoptosis in HeLa cells
}

\author{
YE XU $^{1,2^{*}}$, DI LI $^{3 *}$, LINCHUAN ZENG $^{1}$, CHUNYAN WANG $^{1}$, LILI ZHANG $^{1}$, \\ YAN WANG ${ }^{1}$, YANG YU ${ }^{1}$, SHIBING LIU ${ }^{1}$ and ZHIXIN LI $^{2}$ \\ ${ }^{1}$ Medical Research Laboratory and ${ }^{2}$ Department of Histology and Embryology, Jilin Medical College, Jilin, Jilin 132013; \\ ${ }^{3}$ Department of Urology, Xijing Hospital, Fourth Military Medical University, Xi'an, Shaanxi 710032, P.R. China
}

Received December 3, 2013; Accepted August 8, 2014

DOI: $10.3892 / \mathrm{mmr} .2014 .2683$

\begin{abstract}
Cisplatin is commonly used as a therapeutic agent, despite its known adverse side effects and the occurrence of drug resistance. The development of novel methods for combination therapy with cisplatin is required in order to circumvent these limitations of cisplatin alone. The proteasome inhibitor lactacystin (LAC) has been indicated to produce anti-tumor effects, and has previously been used as an antitumor agent in cancer treatment research; however, its effects in combination with cisplatin treatment are unknown. In the current study, the effects of LAC in combination with cisplatin treatment were investigated in HeLa human cervical cancer (HCC) cells. The results demonstrated that cisplatin treatment inhibited cell growth and induced cell apoptosis. HeLa cell exposure to cisplatin induced endoplasmic reticulum (ER) stress-associated apoptosis, and LAC treatment increased levels of cell apoptosis and the activation of caspase-3. Specifically, LAC treatment increased the cisplatin-induced expression of PDI, GRP78, CHOP, cleaved caspase- 4 and cleaved caspase- 3 . Together, these data indicate that LAC is able to enhance cisplatin cytotoxicity by increasing ER stress-associated apoptosis in HeLa cells.
\end{abstract}

\section{Introduction}

Cisplatin (cis-diamminedichloroplatinum II; CDDP) is one of the most effective chemotherapeutic agents and is widely used for the treatment of solid tumors. The side effects and acquired drug resistance that occur during cisplatin treatment limit

Correspondence to: Professor Zhixin Li, Department of Histology and Embryology, Jilin Medical College, 5 Jilin Street, Changchun, Jilin 130021, P.R. China

E-mail:1zx-62@163.com

*Contributed equally

Key words: lactacystin, cisplatin, apoptosis, ER stress, cervical cancer its clinical use (1-3). The primary cellular target of cisplatin is considered to be nuclear DNA. Cisplatin-induced DNA damage activates various signaling pathways to promote cell death predominantly by inducing apoptosis (4-6). A number of studies have identified that cisplatin can induce endoplasmic reticulum (ER) stress and nucleus-independent apoptotic signaling (7-10).

Various physiological and pathological conditions may lead to ER stress, which results in an accumulation of unfolded or misfolded proteins in the ER lumen $(11,12)$. This cellular stress subsequently causes an activation of the unfolded protein response (UPR), which induces the expression of chaperones and proteins involved in the recovery process. Severe ER stress can lead to cell death, commonly by the activation of intrinsic apoptosis $(13,14)$. The accumulated unfolded or misfolded proteins in the ER are marked for degradation by the ubiquitin-proteasome or autophagy-lysosome pathway $(15,16)$. Previous studies have demonstrated that inhibitors of autophagy, such as 3-methyladenine and chloroquine, effectively enhance the cytotoxicity of chemotherapeutic agents such as cisplatin and S1 by increasing ER stress (17-20). Thus, in the present study, the effect of the proteasome inhibitor lactacystin (LAC) on cisplatin cytotoxicity was assessed. LAC covalently binds to the $\mathrm{N}$-terminal threonine of the 20S proteasome subunit X, and irreversibly modifies all catalytic $\beta$ subunits. LAC inhibits proteases such as cathepsin A and tripeptidyl peptidase II (21-24).

In the present study, it was hypothesized that the use of LAC would increase ER stress-associated apoptosis induced by cisplatin in HeLa human cervical cancer (HCC) cells. HeLa cells were treated with cisplatin, LAC or a combinational therapy incorporating the two drugs simultaneously, and the subsequent effects were analyzed by MTT assay, protein and RNA expression analyses.

\section{Materials and methods}

Cell culture. HeLa human cervical cancer cells were cultured at $37^{\circ} \mathrm{C}$ in an atmosphere of $5 \% \mathrm{CO}_{2}$ and $95 \%$ air, in Iscove's modified Dulbecco's medium (IMDM; Life Technologies, Grand Island, NY, USA) supplemented with $10 \%$ fetal bovine 
serum (FBS; Gibco Life Technologies, Carlsbad, CA, USA) and $100 \mathrm{U} / \mathrm{ml}$ penicillin and $100 \mu \mathrm{g} / \mathrm{ml}$ streptomycin, prior to use in all experiments. The cells were divided into four groups as follows: Non-treated cells; cisplatin-treated cells $(5 \mu \mathrm{g} / \mathrm{ml})$; LAC-treated cells $(10 \mu \mathrm{M})$; Cisplatin $(5 \mu \mathrm{g} / \mathrm{ml})$ and LAC $(10 \mu \mathrm{M})$-treated cells. Cisplatin and LAC were purchased from Sigma-Aldrich (St. Louis, MO, USA)

MTT assay. Cell viability was determined by MTT assay. HeLa cells, during the exponential growth phase, were seeded into 96-well culture plates in $100 \mu \mathrm{l}$ IMDM at a density of $1 \times 10^{4}$ cells/well. After 24 -h incubation, the indicated dose of cisplatin $(5 \mu \mathrm{g} / \mathrm{ml})$ and/or LAC $(10 \mu \mathrm{M})$ was added for 12-h incubation in four parallel wells. MTT assays (Beyotime Institute of Biotechnology, Haimen, China) were performed as follows: $20 \mu \mathrm{l}$ MTT solution $(5 \mathrm{mg} / \mathrm{ml}$ in PBS) was added to the cells for $4 \mathrm{~h}$, after which, $150 \mu \mathrm{l}$ dimethyl sulfoxide (Beijing Chemical Industry Co., Ltd., Beijing, China) was added to each well. The cells were agitated for $10 \mathrm{~min}$, prior to absorbance measurements at $570 \mathrm{~nm}$ using a Microplate Reader (Bio-Rad Laboratories, Hercules, CA, USA). The growth inhibition rate was calculated as \% inhibition $=1$ - absorbance of experimental group/absorbance of control group x 100 . The mean value of the four replica wells was calculated for each treatment group.

Western blotting. Whole-cell protein extracts from HeLa cells were prepared with cell lysis buffer $(50 \mathrm{mM}$ Tris-HCl, $\mathrm{pH} 7.5$; $150 \mathrm{mM} \mathrm{NaCl} ; 1 \mathrm{mM}$ Na2EDTA; $1 \mathrm{mM}$ EDTA; $1 \%$ Triton; $2.5 \mathrm{mM}$ sodium pyrophosphate; $1 \mathrm{mM} \beta$-glycerophosphate; $1 \mathrm{mM} \mathrm{Na}{ }_{3} \mathrm{VO}_{4} ; 1 \mathrm{mM} \mathrm{NaF} ; 1 \mu \mathrm{g} / \mathrm{ml}$ leupeptin; and $1 \mathrm{mM}$ PMSF) for western blotting. The protein extracts were quantified using a Bio-Rad Protein Assay kit (Bio-Rad Laboratories). For Western blot analysis, protein lysates $(30-50 \mu \mathrm{g})$ were separated by $12 \%$ SDS-PAGE and transferred onto Immobilon-P Membranes (EMD Millipore, Billerica, MA, USA). The membranes were blocked with 5\% non-fat dry milk in buffer $(10 \mathrm{mM}$ Tris- $\mathrm{HCl}$, pH 7.6; $100 \mathrm{mM} \mathrm{NaCl}$; and $0.1 \%$ Tween 20) for $2 \mathrm{~h}$ at room temperature and then incubated with the appropriate primary antibodies, including the monoclonal rabbit anti-human Ub and monoclonal rabbit anti-human caspase-3 (1:1,000 dilutions; Epitomics, Burlingame, CA, USA), monoclonal mouse anti-human PDI, monoclonal mouse anti-human p62, monoclonal mouse anti-human Grp78, monoclonal mouse anti-human CHOP, polyclonal rabbit anti-human caspase-4, monoclonal rabbit anti-human caspase-3 and monoclonal mouse anti-human $\beta$-actin (1:1,000 dilutions; Santa Cruz Biotechnology, Inc., Santa Cruz, CA, USA) overnight at $4^{\circ} \mathrm{C}$, followed by incubation with horseradish peroxidase-conjugated secondary antibody (Hangzhou HuaAn Biotechnology Co.. Ltd., HangZhou, China) at 1:2,000 dilution for $1.5 \mathrm{~h}$ at room temperature. The immunoreactive bands were visualized by the diaminobenzidine (Sigma-Aldrich) coloration method. The representative bands were measured using a Tanon Gel Imaging System (Tanon Science and Technology Co., Ltd., Shanghai, China) and analyzed. The protein expression levels were normalized to actin and the ratios of the normalized protein are presented as the means \pm standard deviation from three independent experiments. The protein levels were quantified by densitometry using Quantity One 1-D Analysis Software (Bio-Rad Laboratories).
Immunofluorescence staining and confocal laser microscopy. HeLa cells were cultured on coverslips overnight, and were then treated with cisplatin $(5 \mu \mathrm{g} / \mathrm{ml})$ and/or LAC $(10 \mu \mathrm{M})$ for $12 \mathrm{~h}$. The cells were then fixed with 4\% paraformaldehyde (Beijing Chemical Industry Co., Ltd.), stained with the Hoechst 33342 nuclear stain ( $2 \mu \mathrm{g} / \mathrm{ml}$; Sigma-Aldrich) for $30 \mathrm{~min}$, washed with phosphate-buffered saline (PBS; Beijing Zhongshan Golden Bridge Biological Technology Co., Ltd., Beijing, China), and examined using an Olympus FV1000 confocal laser microscope (Olympus Corporation, Tokyo, Japan) to reveal chromatin condensation. The expression levels of active caspase- 3 and $\gamma-\mathrm{H}_{2} \mathrm{AX}$ were examined by indirect immunofluorescence methods. Briefly, cells were cultured on coverslips overnight and treated with cisplatin $(5 \mu \mathrm{g} / \mathrm{ml})$ and/or LAC $(10 \mu \mathrm{M})$ for $12 \mathrm{~h}$. The cells were then rinsed 3 times with PBS prior to fixation with $4 \%$ paraformaldehyde for $20 \mathrm{~min}$. The cells were then permeabilized with $0.1 \%$ Triton X-100 (Beijing Dingguo Changsheng Biotechnology Co., Ltd., Beijing, China) for $5 \mathrm{~min}$ and blocked with bovine serum albumen (Beijing Dingguo Changsheng Biotechnology Co., Ltd.), prior to incubation with primary antibodies against active caspase-3 (Epitomics) and $\gamma-\mathrm{H}_{2} \mathrm{AX}$ (Cell Signaling Technology, Inc., Danvers, MA, USA) (1:100 dilution) overnight at $4^{\circ} \mathrm{C}$. The cells were then incubated with Alexa Fluor543/488-conjugated secondary antibody (1:400; Invitrogen Life Technologies, Carlsbad, CA, USA) for $1 \mathrm{~h}$, then stained with the Hoechst $33342(2 \mu \mathrm{g} / \mathrm{ml})$ for $2 \mathrm{~min}$, and washed with PBS 3 times. The cells were mounted and examined by confocal laser microscopy.

Statistical analysis. Data are representative of three independent experiments each conducted in triplicate. Statistical analysis of the data was performed using one-way analysis of variance. Tukey's post-hoc test was used to determine the significance for all pairwise comparisons of interest. $\mathrm{P}<0.05$ was considered to indicate a statistically significant difference.

\section{Results}

LAC potentiates cell growth inhibition induced by cisplatin. Based on previous studies, HeLa cells were treated with the indicated doses of cisplatin and/or LAC for $12 \mathrm{~h}$, and then the growth inhibition was examined by MTT assay. It was observed that cisplatin inhibited the growth of HeLa cells. MTT assay indicated that LAC alone exerted no significant effect on cell viability, and LAC treatment enhanced the cytotoxic effect of cisplatin when administered in combination (Fig. 1A). Changes to cellular morphology were observed under a inverted phase contrast microscope. Compared with the controls, round and fragile cells were detected in the cisplatin treatment group. The number of round and fragile cells was increased in the group treated with cisplatin combined with LAC (Fig. 1B).

LAC increases cisplatin-induced cell apoptosis. The levels of apoptosis were analyzed in order to whether LAC may potentiate the apoptosis induced by cisplatin in HeLa cells. Apoptotic chromatin condensation was analyzed with Hoechst 33342 staining and confocal microscopy. As compared with the control cells, cisplatin-induced apoptotic chromatin condensation was clearly observed. As compared with the cisplatin-treated group, the cells treated with both 
A

B
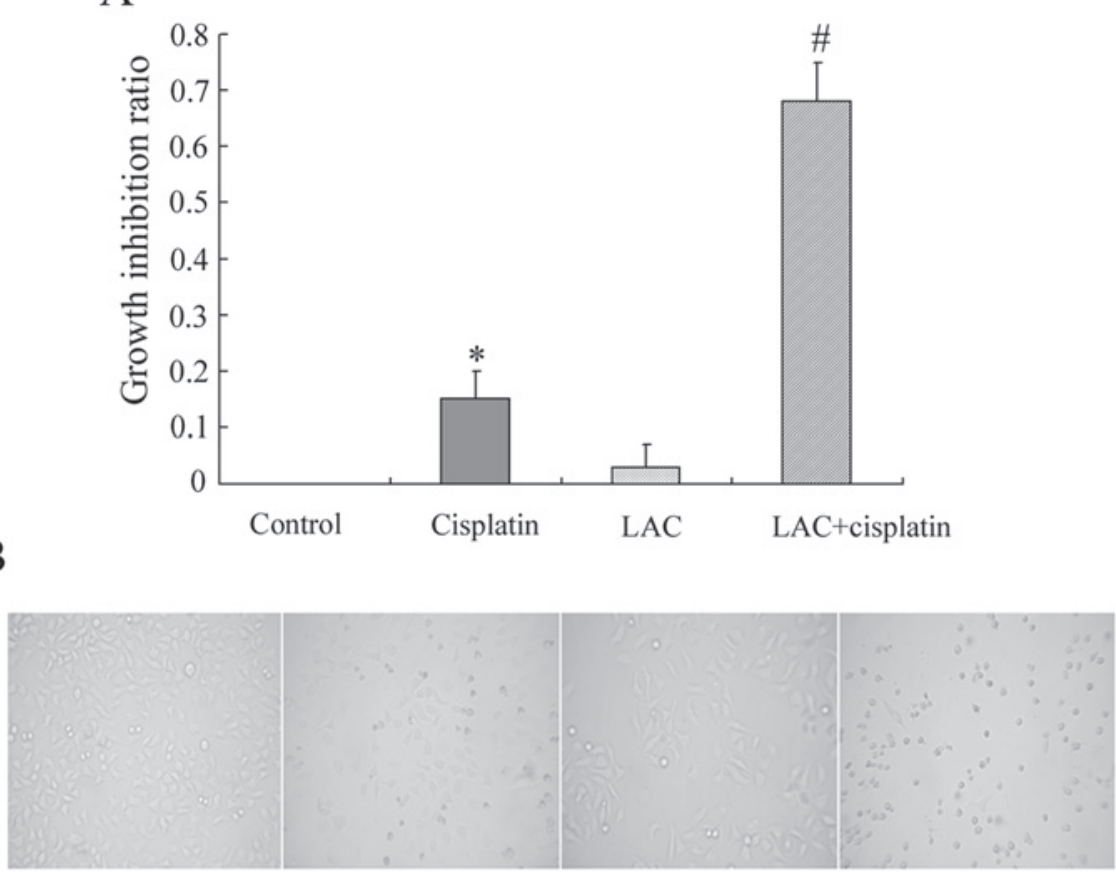

Figure 1. LAC increases the growth inhibition rate induced by cisplatin in HeLa human cervical cancer cells. HeLa cells were treated with cisplatin $(5 \mu \mathrm{g} / \mathrm{ml})$ and/or LAC $(10 \mu \mathrm{M})$ for $12 \mathrm{~h}$. (A) Cell viability was determined by MTT assay. (B) Images were captured with an inverted phase contrast microscope at a magnification of $x 100$. Data are presented as the mean \pm standard deviation, $n=3$. ${ }^{*} \mathrm{P}<0.05$ vs. control, ${ }^{\text {}} \mathrm{P}<0.05$ vs. cisplatin. LAC, lactacystin.

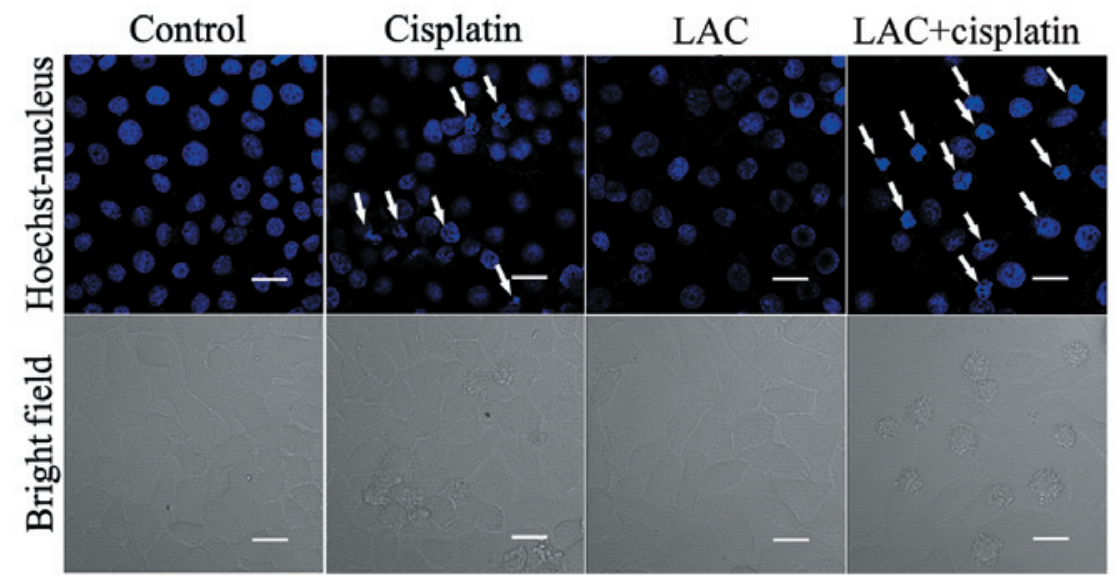

Figure 2. LAC increases cisplatin-induced apoptosis in HeLa human cervical cancer cells. HeLa cells were treated with cisplatin ( $5 \mu \mathrm{g} / \mathrm{ml})$ and/or LAC (10 $\mu \mathrm{M})$ for $12 \mathrm{~h}$ then stained with Hoechst 33342. Cell morphology was observed by confocal microscopy (Scale bar, $20 \mu \mathrm{m}$, arrows, apoptotic cells; magnification, x800). LAC, lactacystin.

cisplatin and LAC exhibited a marked increase in the levels of apoptotic chromatin condensation (Fig. 2).

Caspase-3 functions as an executioner molecule during apoptosis, and its activation reflects the initiation of apoptosis. Using confocal microscopy, the activation of caspase-3 was detected in the cisplatin-treated cells and those treated with cisplatin combined with LAC (Fig. 3). The expression of caspase-3, indicated by indirect red fluorescence, was stronger in the cells treated with cisplatin combined with LAC compared with cells treated with cisplatin alone, indicating that the combined treatment increased caspase-3 activation. These results indicate that LAC can efficiently increase the apoptosis induced by cisplatin in HeLa cells.
LAC increases cisplatin-induced ER stress. Previous studies have indicated that cisplatin can induce ER stress by misfolded protein accumulation. Misfolded proteins may be ubiquitinated, marking them for degradation (17). Therefore the expression levels of ubiquitin (Ub), ER chaperone protein disulfide isomerase (PDI; which reflects the occurrence of ER stress), and p62 (an adaptor that transports the ubiquitinated proteins) were analyzed by western blotting. It was observed that cisplatin and LAC treatments induced a higher level of Ub. The combination of cisplatin and LAC markedly increased the ubiquitination of proteins. Cisplatin and LAC increased the expression of PDI compared with the control cells, and combination treatment increased the expression of PDI compared 
Hoechst-nucleus Alexa Fluor543- $\quad$ Merge $\quad$ Bright field

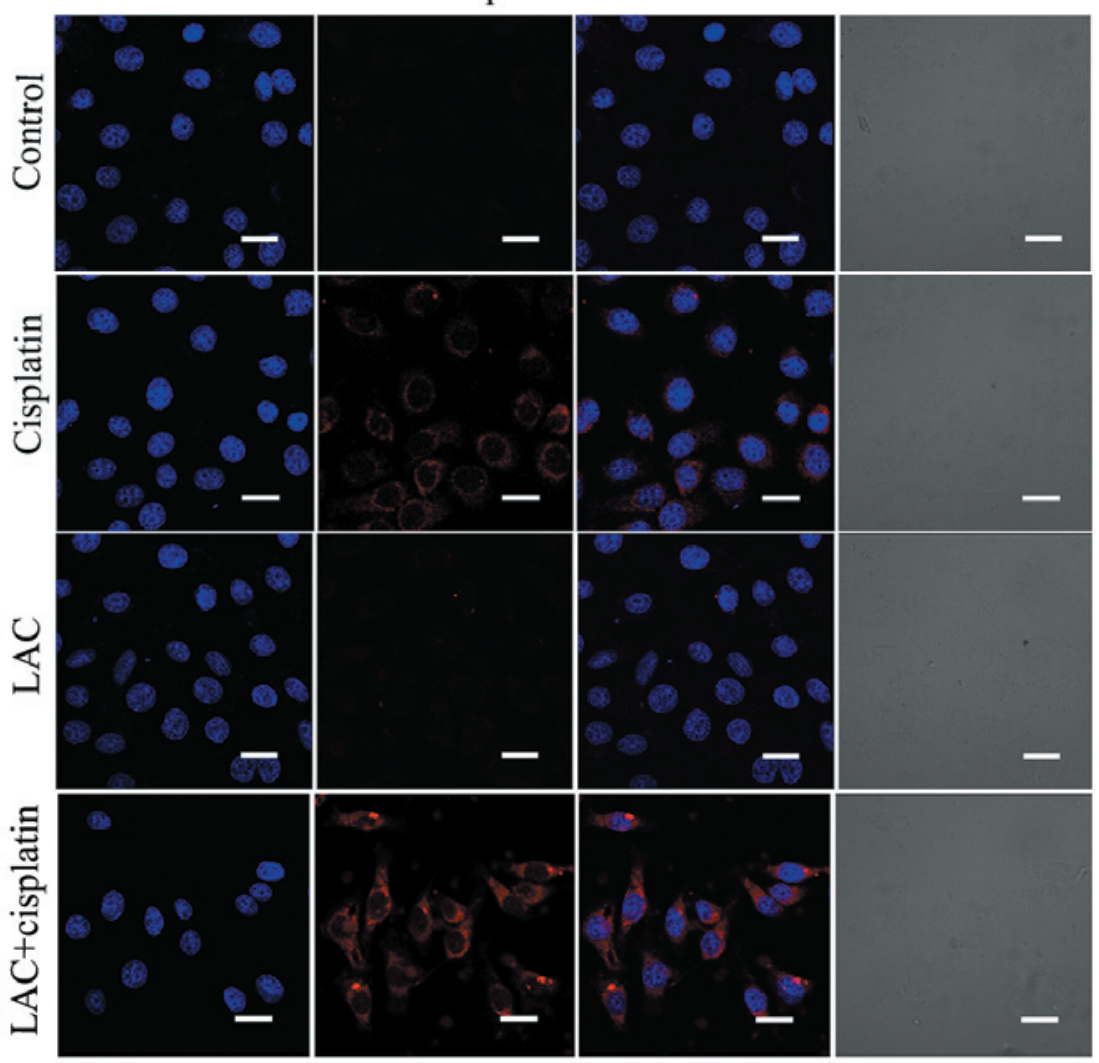

Figure 3. LAC increases the expression of active caspase-3 in HeLa human cervical cancer cells. HeLa cells were treated with cisplatin (5 $\mu \mathrm{g} / \mathrm{ml})$ and/or LAC $(10 \mu \mathrm{M})$ for $12 \mathrm{~h}$. The expression of active caspase-3 was detected by confocal microscopy with varying treatments (scale bar, $20 \mu \mathrm{m}$; magnification, $\mathrm{x} 800$ ). LAC, lactacystin.

A

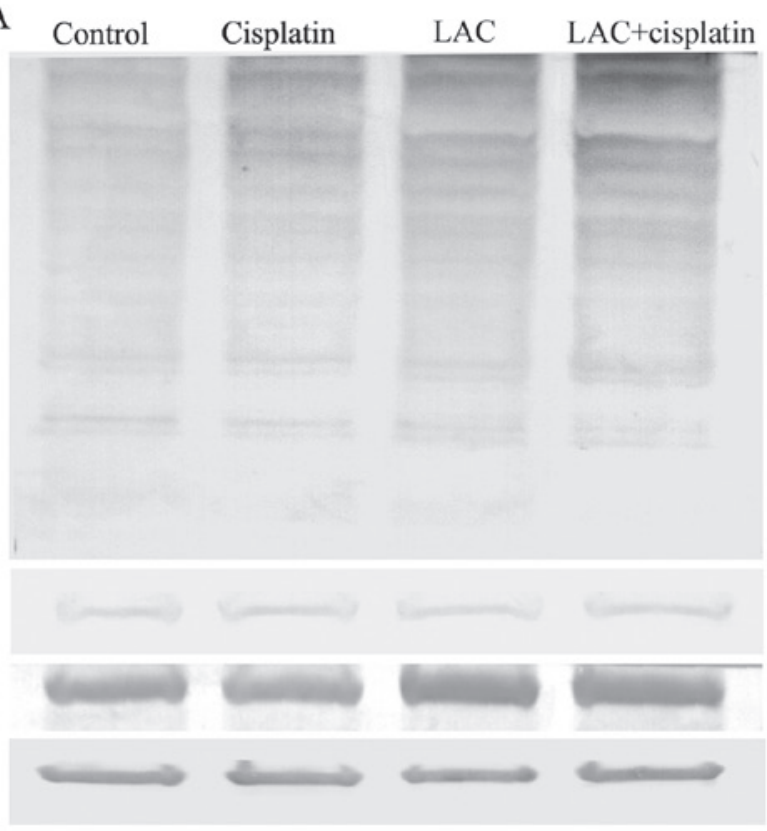

B $\quad \square$ Control $\square$ Cisplatin $\square$ LAC $\square$ LAC+cisplatin

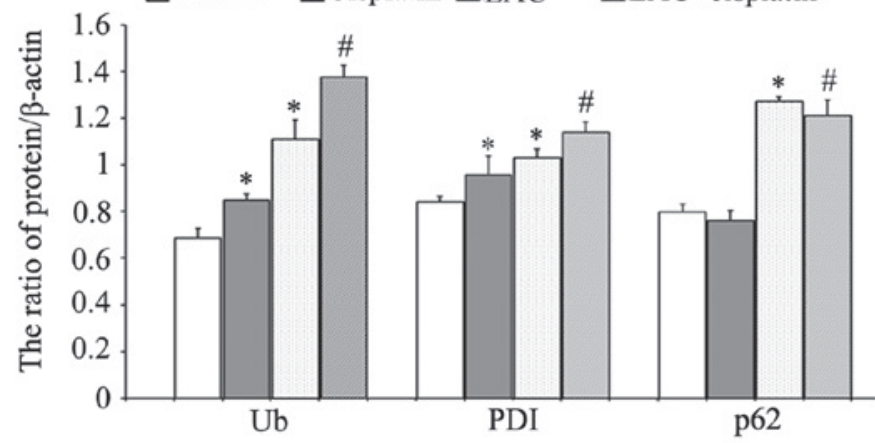

PDI

p62

$\beta$-actin

Figure 4. LAC increased cisplatin-induced ER stress in HeLa human cervical cancer cells. (A) HeLa cells were treated with cisplatin (5 $\mu$ g/ml) and/or LAC $(10 \mu \mathrm{M})$ for $12 \mathrm{~h}$. Western blot analysis of Ub, PDI and p62. (B) Quantification of the protein levels. Data are presented as the mean \pm standard deviation, $\mathrm{n}=3$. ${ }^{*} \mathrm{P}<0.05$ vs. control, ${ }^{\#} \mathrm{P}<0.05$ vs. cisplatin. LAC, lactacystin; ER, endoplasmic reticulum; Ub, ubiquitinated protein; PDI, protein disulfide isomerase.

with the cisplatin group. In addition, the protein level of p62 showed a slight reduction following cisplatin treatment, whilst LAC treatment increased its level in cells treated with LAC alone or when combined with cisplatin (Fig. 4). These 
A

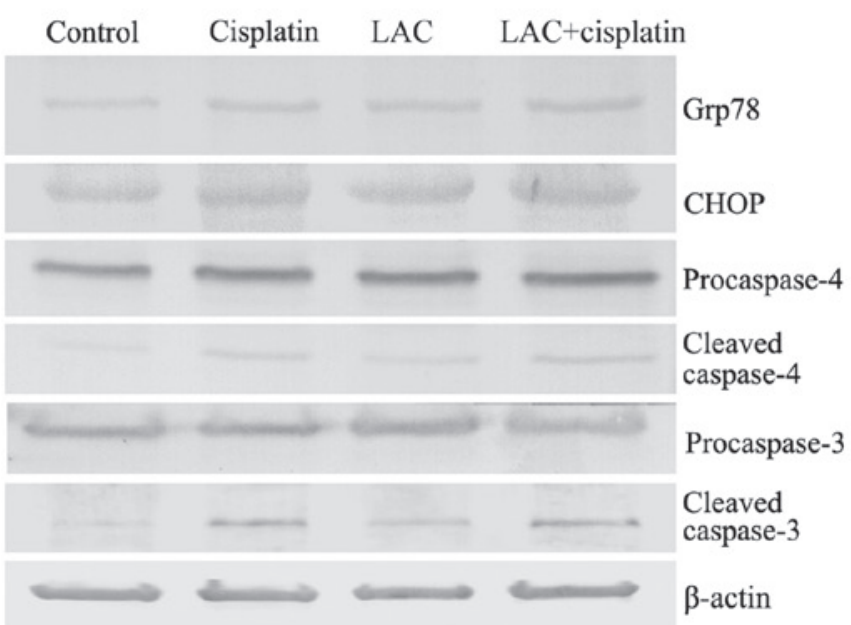

$\mathrm{B}$

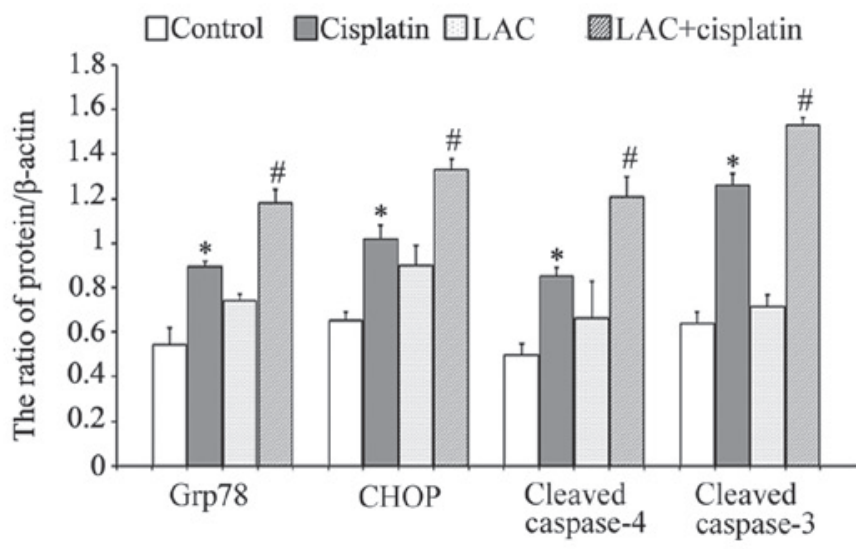

Figure 5. LAC increased cisplatin-induced endoplasmic reticulum stress-associated apoptosis in HeLa human cervical cancer cells. (A) HeLa cells were treated with cisplatin $(5 \mu \mathrm{g} / \mathrm{ml})$ and/or LAC $(10 \mu \mathrm{M})$ for $12 \mathrm{~h}$. Western blot analysis of grp78, CHOP, caspase-4, cleaved caspase-4, caspase-3 and cleaved caspase-3. (B) Quantitation of the protein levels. Data are presented as the mean \pm standard deviation, $\mathrm{n}=3$. ${ }^{*} \mathrm{P}<0.05$ vs. control, ${ }^{\#} \mathrm{P}<0.05$ vs. cisplatin. LAC, lactacystin; grp78, glucose-regulated protein-78; CHOP, 153/C/EBP homology protein.

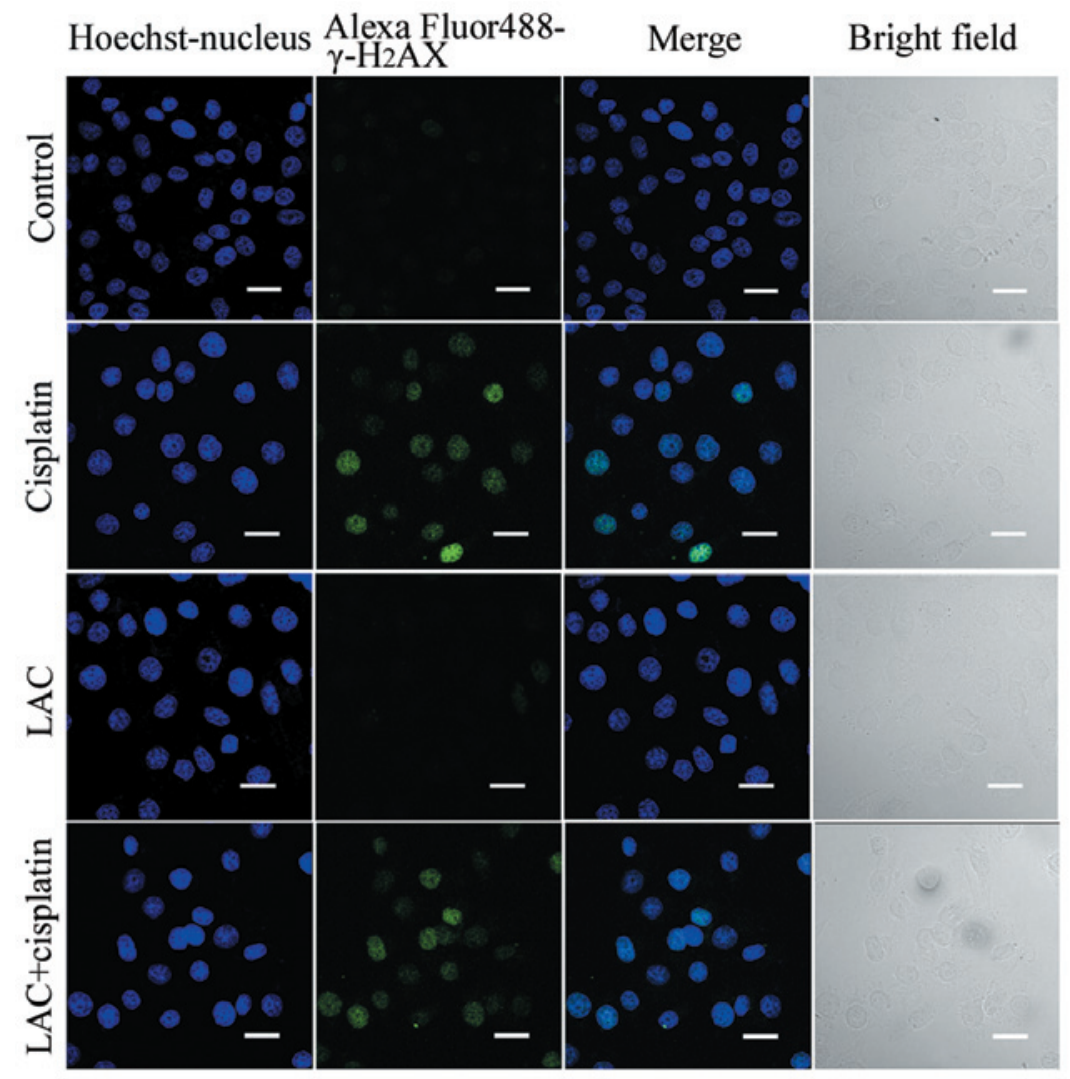

Figure 6. $\mathrm{NH}_{4} \mathrm{Cl}$ does not increase the phosphorylation of $\mathrm{H}_{2} \mathrm{AX}$. HeLa cells were treated with cisplatin (5 $\left.\mu \mathrm{g} / \mathrm{ml}\right)$ and/or LAC (10 $\left.\mu \mathrm{M}\right)$ for $12 \mathrm{~h}$. The expression of $\gamma-\mathrm{H}_{2} \mathrm{AX}$ was detected by confocal microscopy with varying treatments (Scale bar, $20 \mu \mathrm{m}$; magnification, x800). LAC, lactacystin.

results indicate that LAC can increase cisplatin-induced ER stress in HeLa cells.

LAC increases cisplatin-induced ER stress-associated apoptosis. Glucose-regulated protein-78 (Grp78) is an ER chaperone protein, which can be upregulated by ER stress (18). The growth-arrest and DNA-damage-inducible gene, 153/C/EBP homology protein (GADD153/CHOP), is involved in ER stress-induced cell death; sustained ER stress induces caspase-mediated apoptosis $(17,18)$. Caspase- 4 is an ER-resident caspase that, similar to murin caspase-12, is processed in response to ER stress and is activated during ER stress-induced apoptosis. Using western blot analysis, it was observed that cisplatin induced the upregulation of 
Grp78, CHOP, and cleaved caspases 3 and 4. Compared with cisplatin, LAC increased the expression levels of all these proteins (Fig. 5). These results indicate that LAC increased cisplatin-induced ER stress-associated apoptosis.

LAC does not enhance the level of cisplatin-induced DNA double-strand breaks (DSB). Cisplatin acts to damage DNA and inhibit DNA synthesis, thus resulting in cancer-cell death (6). Therefore it was hypothesized in the current study that LAC may increase DNA breakage induced by cisplatin. DNA DSB are able to induce phosphorylation of $\mathrm{H}_{2} \mathrm{AX}$ at a conserved serine 139 residue in the $\mathrm{C}$ terminal region, leading to the formation of $\gamma-\mathrm{H}_{2} \mathrm{AX}$. This molecule is commonly used as a DNA DSB marker. Using confocal microscopy, the expression of $\gamma-\mathrm{H}_{2} \mathrm{AX}$, reported by indirect green fluorescence, was visualized in both the cells treated for $12 \mathrm{~h}$ with cisplatin and cisplatin combined with LAC (Fig. 6). These results indicate that LAC does not enhance the DSB induced by cisplatin in HeLa cells.

\section{Discussion}

Cisplatin has been used as a chemotherapeutic agent in the clinical setting for many years, with positive effects against numerous types of solid tumors, including cervical cancer (1). The produced side-effects and drug resistance of cisplatin limit its use. The predominant pathway of cell death that is induced by cisplatin is a caspase-dependent intrinsic apoptotic pathway involving the mitochondria and $\operatorname{ER}(6,10,25)$.

The ER has been previously reported to be a target of cisplatin-induced apoptosis $(17,18)$. It was demonstrated that cisplatin was able to induce ubiquitinated protein accumulation and lead to ER stress in HeLa and SKOV3 cells $(17,18)$. The following three ER sensors have been identified: PKR-like ER kinase, inositol requiring enzyme 1 and activating transcription factor 6 in UPR induction (26). Upon induction of ER stress is induced, the cell upregulates several ER resident chaperones, such as GRP78 and PDI, to re-establish ER homeostasis. Simultaneously, the misfolded or unfolded proteins are transported to be degraded by the ubiquitin-proteasome or autophagy-lysosome pathways $(11,12,26)$. P62 is a multifunctional molecule, functioning as an adaptor to bind ubiquitinated proteins and transport them for degradation. Once the proteins are degraded, bound p62 molecules are also degraded $(27,28)$. Sustained and unabated ER stress induces the activation of apoptosis. CHOP (GADD153) is a member of the C/EBP family of bZIP transcription factors, and its expression is upregulated by ER stress. CHOP participates in ER-stress-corrective actions through induction or suppression of a number of genes. Prolonged activation of CHOP can trigger apoptosis in cells under certain conditions $(29,30)$.

In the present study, it was demonstrated that cisplatin treatment inhibited cell growth and induced cell apoptosis in HeLa cells. In addition, exposure to cisplatin increased the expression of Ub, PDI and GRP78 and upregulated the level of CHOP and cisplatin treatment induced the activation of caspase- 4 and caspase-3. Together, these findings indicate that cisplatin can induce ER stress-associated apoptosis in human cervical cancer HeLa cells. LAC treatment combined with cisplatin potentiated the effects of cisplatin alone. DNA damage is considered an indicator of apoptosis in cisplatin cytotoxicity. $\mathrm{H}_{2} \mathrm{AX}$ phosphory- lation occurs in response to cisplatin-induced DNA lesions. The formation of $\gamma-\mathrm{H}_{2} \mathrm{AX}$ is a useful indicator of cisplatin-induced DNA damage (31). Thus, the changes to $\gamma-\mathrm{H}_{2} \mathrm{AX}$ formation in cells treated with cisplatin combined with LAC was investigated in the present study. However, there was no difference between cells treated with cisplatin alone and those treated with cisplatin combined with LAC. These results indicate that LAC enhanced cisplatin cytotoxicity by increasing ER stress-associated apoptosis, rather than by increasing DNA damage.

In conclusion, it was demonstrated that cisplatin treatment induced ER stress-associated apoptosis in human cervical cancer HeLa cells. LAC treatment combined with cisplatin increased the cell growth inhibition rate, cell apoptosis and activation of caspase-3. Additionally, LAC treatment increased the cisplatin-induced expression levels of PDI, GRP78, CHOP, cleaved caspase- 4 and cleaved caspase- 3 . These data indicate that LAC is able to enhance cisplatin cytotoxicity by increasing ER stress-associated apoptosis, and it has the potential to improve the results of cisplatin chemotherapy.

\section{Acknowledgements}

The present study was supported by grants from the National Natural Science Foundation of China (nos. 81372793 and 81100808), the Natural Science Foundation of Jilin Province (no. 201015240) and the Department of Education of Jilin Province Project (no. 2013361).

\section{References}

1. Muggia F: Platinum compounds 30 years after the introduction of cisplatin: implications for the treatment of ovarian cancer. Gynecol Oncol 112: 275-281, 2009.

2. Florea AM and Büsselberg D: Cisplatin as an anti-tumor drug: cellular mechanisms of activity, drug resistance and induced side effects. Cancers (Basel) 3: 1351-1371, 2011.

3. Galluzzi L, Senovilla L, Vitale I, Michels J, Martins I, Kepp O, Castedo M and Kroemer G: Molecular mechanisms of cisplatin resistance. Oncogene 31: 1869-1883, 2012.

4. Eastman A: The formation, isolation and characterization of DNA adducts produced by anticancer platinum complexes. Pharmacol Ther 34: 155-166, 1987.

5. Woźniak K and Błasiak J: Recognition and repair of DNA-cisplatin adducts. Acta Biochim Pol 49: 583-596, 2002.

6. Basu A and Krishnamurthy S: Cellular responses to Cisplatin-induced DNA damage. J Nucleic Acids 2010: pii: 201367, 2010.

7. Mandic A, Hansson J, Linder S and Shoshan MC: Cisplatin induces endoplasmic reticulum stress and nucleus-independent apoptotic signaling. J Biol Chem 278: 9100-9106, 2003.

8. Liu H and Baliga R: Endoplasmic reticulum stress-associated caspase 12 mediates cisplatin-induced LLC-PK1 cell apoptosis. J Am Soc Nephrol 16: 1985-1992, 2005.

9. Peyrou M, Hanna PE and Cribb AE: Cisplatin, gentamicin, and p-aminophenol induce markers of endoplasmic reticulum stress in the rat kidneys. Toxicol Sci 99: 346-353, 2007.

10. Yu F, Megyesi J and Price PM: Cytoplasmic initiation of cisplatin cytotoxicity. Am J Physiol Renal Physiol 295: F44-F52, 2008.

11. Berridge MJ: The endoplasmic reticulum: a multifunctional signaling organelle. Cell Calcium 32: 235-249, 2002.

12. Jørgensen MM, Bross P and Gregersen N: Protein quality control in the endoplasmic reticulum. APMIS Suppl 109: 86-91, 2003.

13. Rao RV, Ellerby HM and Bredesen DE: Coupling endoplasmic reticulum stress to the cell death program. Cell Death Differ 11: 372-380, 2004.

14. Kim R, Emi M, Tanabe K and Murakami S: Role of the unfolded protein response in cell death. Apoptosis 11: 5-13, 2006.

15. Benbrook DM and Long A: Integration of autophagy, proteasomal degradation, unfolded protein response and apoptosis. Exp Oncol 34: 286-297, 2012. 
16. Høyer-Hansen $M$ and Jäättelä $M$ : Connecting endoplasmic reticulum stress to autophagy by unfolded protein response and calcium. Cell Death Differ 14: 1576-1582, 2007.

17. Yu H, Su J, Xu Y, Kang J, Li H, Zhang L, Yi H, Xiang X, Liu F and Sun L: p62/SQSTM1 involved in cisplatin resistance in human ovarian cancer cells by clearing ubiquitinated proteins. Eur J Cancer 47: 1585-1594, 2011.

18. Xu Y, Yu H, Qin H, Kang J, et al: Inhibition of autophagy enhances cisplatin cytotoxicity through endoplasmic reticulum stress in human cervical cancer cells. Cancer Lett 314: 232-243, 2012.

19. Zhong JT, Xu Y, Yi HW, et al: The BH3 mimetic S1 induces autophagy through ER stress and disruption of Bcl-2/Beclin 1 interaction in human glioma U251 cells. Cancer Lett 323: 180-187, 2012.

20. Liu N, Xu Y, Sun JT, et al: The BH3 mimetic S1 induces endoplasmic reticulum stress-associated apoptosis in cisplatin-resistant human ovarian cancer cells although it activates autophagy. Onco Rep 30: 2677-2684, 2013

21. Fenteany G, Standaert RF, Lane WS, Choi S, Corey EJ and Schreiber SL: Inhibition of proteasome activities and subunit-specific amino-terminal threonine modification by lactacystin. Science 268: 726-731, 1995.

22. Craiu A, Gaczynska M, Akopian T, et al: Lactacystin and clasto-lactacystin beta-lactone modify multiple proteasome beta-subunits and inhibit intracellular protein degradation and major histocompatibility complex class I antigen presentation. J Biol Chem 272: 13437-13445, 1997.
23. Ostrowska H, Wojcik C, Omura S and Worowski K: Lactacystin, a specific inhibitor of the proteasome, inhibits human platelet lysosomal cathepsin A-like enzyme. Biochem Biophys Res Commun 234: 729-732, 1997.

24. Geier E, Pfeifer G, Wilm M, et al: A giant protease with potential to substitute for some functions of the proteasome. Science 283: 978-981, 1999.

25. Rebillard A, Lagadic-Gossmann D and Dimanche-Boitrel MT: Cisplatin cytotoxicity: DNA and plasma membrane targets. Curr Med Chem 15: 2656-2663, 2008.

26. Ogata M, Hino S, Saito A, Morikawa K, et al: Autophagy is activated for cell survival after endoplasmic reticulum stress. Mol Cell Biol 26: 9220-9231, 2006.

27. Lin X, Li S, Zhao Y, Ma X, Zhang K, He X and Wang Z: Interaction domains of p62: a bridge between p62 and selective autophagy. DNA Cell Biol 32: 220-227, 2013.

28. Tanida I: Autophagosome formation and molecular mechanism of autophagy. Antioxid Redox Signal 14: 2201-2214, 2011.

29. Szegezdi E, Logue SE, Gorman AM and Samali A: Mediators of endoplasmic reticulum stress-induced apoptosis. EMBO Rep 7: 880-885, 2006.

30. Tabas I and Ron D: Integrating the mechanisms of apoptosis induced by endoplasmic reticulum stress. Nat Cell Biol 13: 184-190, 2011

31. Olive PL and Banáth JP: Kinetics of $\mathrm{H}_{2} \mathrm{AX}$ phosphorylation after exposure to cisplatin. Cytometry B Clin Cytom 76: 79-90, 2009. 